\title{
Effects of Seasonal Variation on Performance of Conventional Wastewater Treatment System
}

\author{
Francis Ongachi Olal \\ Department of Physical Sciences, Rongo University, P.O. Box 103 -40404 Rongo, Kenya \\ E-mail: olalf12@gmail.com
}

\begin{abstract}
The study was to determine the seasonal differences of conventional wastewater treatment process. This was done by sampling and analyses of wastewater samples from four different points during the dry and wet seasons of the year 2019. Water samples were taken from influent point, primary effluent, trickling filter effluent and final effluent. Gravimetric method was used in determining Total Suspended Solids (TSS) and Total Dissolved Solids (TDS). The $\mathrm{BOD}_{5}$ technique was used for determination of Biological Oxygen Demand (BOD) and the digestion method was used for determination Chemical Oxygen Demand (COD). Temperature, $\mathrm{pH}$ and conductivity were measured using respective meters. Analysis of Variance showed that there was significant difference $(p<0.05)$ in all the parameters quantified at all the points of treatment during the two seasons. The results showed that BOD and COD both reduced from one point to the next during the two seasons of study. The TSS levels increased after primary pond effluent undergoing treatment at the trickling filter and the temperature also increased after the trickling filter effluent undergoing treatment at oxidation ponds. The levels of conductivity and TDS decreased from one treatment stage to the next during dry season but during the wet season the levels of these parameters increased from one stage to the next except that the levels reduced after the primary pond effluent underwent treatment at the trickling filter. The various stages of wastewater treatment plant under were effective during the two seasons however, wet season recorded lower figures for most of the parameters.
\end{abstract}

Keywords: effluent, influent, wastewater, seasonal variation, ponds

DOI: $10.7176 / \mathrm{JEES} / 11-7-06$

Publication date:July $31^{\text {st }} 2021$

\section{Introduction}

Wastewater contains high levels of organic matter from industrial, agricultural and human wastes. The organic matter is removed by the process of wastewater treatment. Wastewater treatment involves physical, biological and chemical removal of organic matter and other constituents (Ramesh, 2004).

The most important reasons for treating wastewater are the prevention of pollution of portable water and protection of public health (Akpor and Muchie, 2011). In developing countries, wastewater is insufficiently treated because of rise in population in urban areas (UNEP, Nairobi 2011). Release of insufficiently treated effluent containing huge amounts of nutrients to the waterways might allow poses threat to human safety (Wakelin et al., 2008). Communities living downstream are at high risk of contracting diseases due to increased microbial pathogens and deteriorating physico-chemical parameters (Wakelin et al., 2008). However, sufficiently treated effluent can be discharged into, streams, rivers wetland or lagoons (Fatta et al,. 2005).

Safeguarding of river, which is always the recipient of wastewater effluent, requires effective monitoring of physicochemical and microbiological parameters (Chandra et al., 2006). Monitoring of phycicochemical parameters during wastewater treatment helps in assessing the quality of the final effluent before being released to the river where we have aquatic life as well as human beings using the same water downstream for a range of purposes. Many studies have been

\section{Materials and Methods}

The study was carried out at Huruma Sewage Treatment Plant in Eldoret town, Uasin - Gishu County, Kenya. The plant employs screens, trickling filters and oxidation ponds for wastewater treatment. In addition it has flow chamber where the water in the sedimentation pond effluent are pumped back to mix with the primary pond effluent. The study was carried out in the months of February and April to represent the dry and wet seasons respectively. The samples were taken at exactly 10.00 am from various points of wastewater treatment namely; influent, Primary effluent, secondary effluent and final effluent. All the parameters were analysed in triplicates; Temperature and $\mathrm{pH}$ were tested in situ while BOD, COD, TSS, TDS and conductivity were analysed at the Eldoret Water and Sanitation Company (ELDOWAS) laboratory. 


\subsection{Biological Oxygen Demand (BOD)}

The procedure on the BOD track manual was used. Nitrification inhibitor powder was dispensed into the empty sterile BOD bottle. Collected samples of 1 litre were homogenised in a blender. The $\mathrm{pH}$ of the sample was adjusted to a range of 6.5 and 7.5 with sulphuric acid or sodium hydroxide. The wastewater samples were measured and poured into BOD bottles. A $3.8 \mathrm{~cm}$ magnetic stir bar was placed in each sample bottle and stopcock grease was applied to the seal lip of each bottle and to the cap of each seal cap. One gram Lithium hydroxide powder pillow was added to each seal cap. The bottles were incubated for five days in a BOD incubator at $20^{\circ} \mathrm{C}$ and which the concentration of BOD $\mathrm{n} \mathrm{mg} / \mathrm{L}$ was recorded.

\subsection{Chemical Oxygen Demand (COD)}

Chemical oxygen demand was determined as described in chemical oxygen demand manual where $100 \mathrm{ml}$ of the samples collected were first homogenized in a blender. Two millilitres of the homogenised samples collected from the influent and primary pond effluent were pipetted into the high range reagents. The same volume was pipetted from trickling filter effluent and final effluents were added to low range reagents. Two millilitres of deionised water was added to each of the two reagents to produce a blank, then the vials were inverted gently several times and placed in a COD reactor digestor which had been preheated to a temperature of $150^{\circ} \mathrm{C}$ and left to heat for two hours. After this duration the vials containing the samples were cooled to room temperature and finally a programmed spectrophotometer machine was used to read the COD results.

\subsection{Total Suspended Solids (TSS)}

The TSS was obtained by the procedure described by (Eaton et al., 1995). A glass filter was dried by placing it in an oven with a temperature of $103^{\circ} \mathrm{C}$ for 60 minutes, removed and put in a dessicator to cool for 60 minutes and weighed. A $100 \mathrm{ml}$ of the homogenised sample was filtered through the glass filter. The weight of the sample was obtained by using the formula;

$\operatorname{TSS}(\mathrm{mg} / \mathrm{L})=\underline{(\mathrm{A}-\mathrm{B}) \times 1000}$

Sample volume

Where $\mathrm{A}=$ weight of filter plus dried residue in $\mathrm{mg}$

$\mathrm{B}=$ weight of filter in $\mathrm{mg}$.

\subsection{Total Dissolved Solids (TDS)}

The filtrate obtained from the testing for total suspended solids described in 2.3 above was utilized for testing for TDS by transferring it to weighed evaporating dish and evaporated to dryness on a steam bath. This was followed by drying for one hour at $180^{\circ} \mathrm{C}$ then cooling for one hour in a dessicator.

Weight of TDS was obtained using the formulae by

$\operatorname{TSS}(\mathrm{mg} / \mathrm{L})=(\mathrm{A}-\mathrm{B}) \times 1000$

Sample volume

Where $\mathrm{A}=$ weight of dried residue plus dish in $\mathrm{mg}$

$\mathrm{B}=$ weight of dish in $\mathrm{mg}$

\subsection{Conductivity}

Conductivity was measured using conductivity meter

\section{6. pH}

$\mathrm{pH}$ meter was used to determine the $\mathrm{pH}$ in situ.

\subsection{Temperature}

Thermometer was used to measure the temperature.

\subsection{Statistical Analysis}

The data collected during the two seasons at the influent, primary pond effluent, trickling filter effluent and final effluent were analysed using Analysis of Variance (ANOVA) procedure using SAS 9.2 software. This was done for seven parameters; BOD, COD, TSS, TDS, conductivity, $\mathrm{pH}$ and temperature. Confidence level of $95 \%$ was used then the findings presented using bar graphs.

\section{Results}

Analysis of variance (ANOVA) was used to analyze the parameters collected from various points of Huruma sewage treatment plant during the two months of study as shown in Table 3.1 and Table 3.2. Figure 3.1 and Figure 3.2 demonstrates the trends of the parameters studied during the wastewater treatment process. 
Table 3.1: Physicochemical parameters at the various points -Dry Season

\begin{tabular}{|l|l|l|l|l|l|l|l|}
\hline & $\mathrm{pH}$ & COND & TEMP & COD & BOD & TDS & TSS \\
\hline INF & 7.8 & 500 & 22 & 1500 & 700 & 400 & 200 \\
\hline PRI & 7.2 & 1500 & 21 & 400 & 200 & 1000 & 100 \\
\hline TF & 8.2 & 1100 & 15 & 250 & 100 & 800 & 80 \\
\hline FE & 8.0 & 1000 & 20 & 200 & 60 & 700 & 60 \\
\hline
\end{tabular}

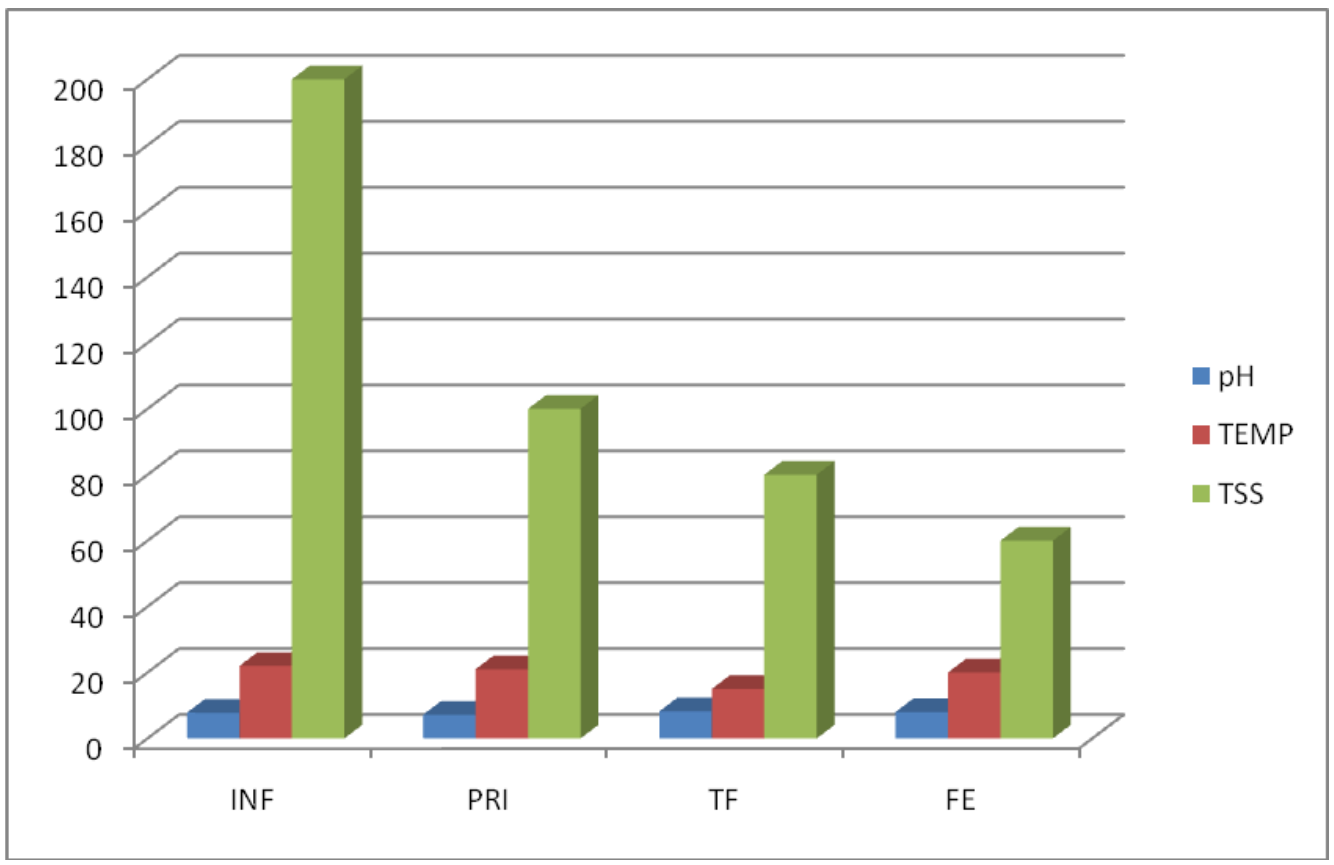

Figure 3.2 (a): Physicochemical parameters at the various sampling points -Dry season 


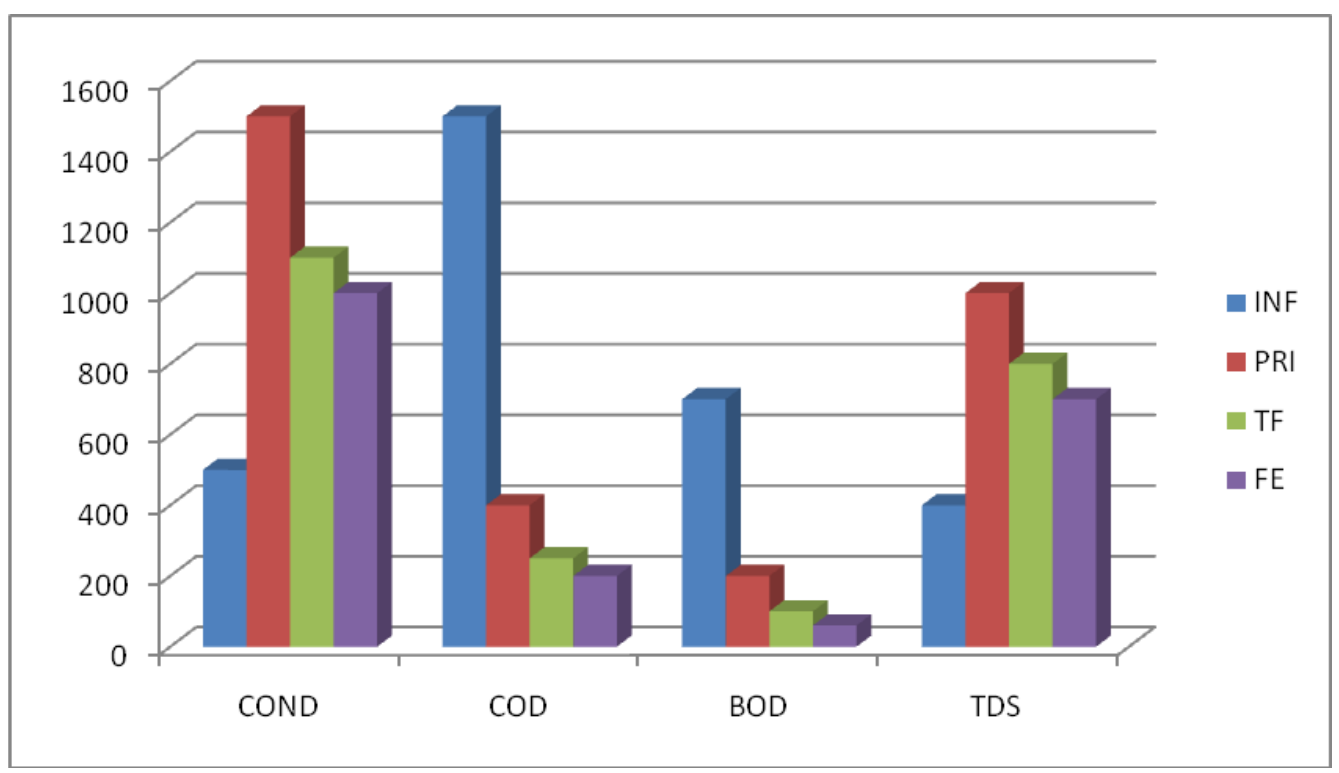

Figure 3.2 (a): Physicochemical parameters at the various sampling points -Dry season

Table 3.2: Physicochemical parameters at the various points - Wet season

\begin{tabular}{|l|l|l|l|l|l|l|l|}
\hline & $\mathrm{pH}$ & COND & TEMP & COD & BOD & TDS & TSS \\
\hline INF & 7.0 & 420 & 22 & 1200 & 500 & 300 & 220 \\
\hline PRI & 6.8 & 470 & 15 & 180 & 80 & 320 & 80 \\
\hline TF & 7.4 & 430 & 15 & 120 & 60 & 310 & 100 \\
\hline FE & 8.0 & 500 & 21 & 100 & 30 & 340 & 80 \\
\hline
\end{tabular}




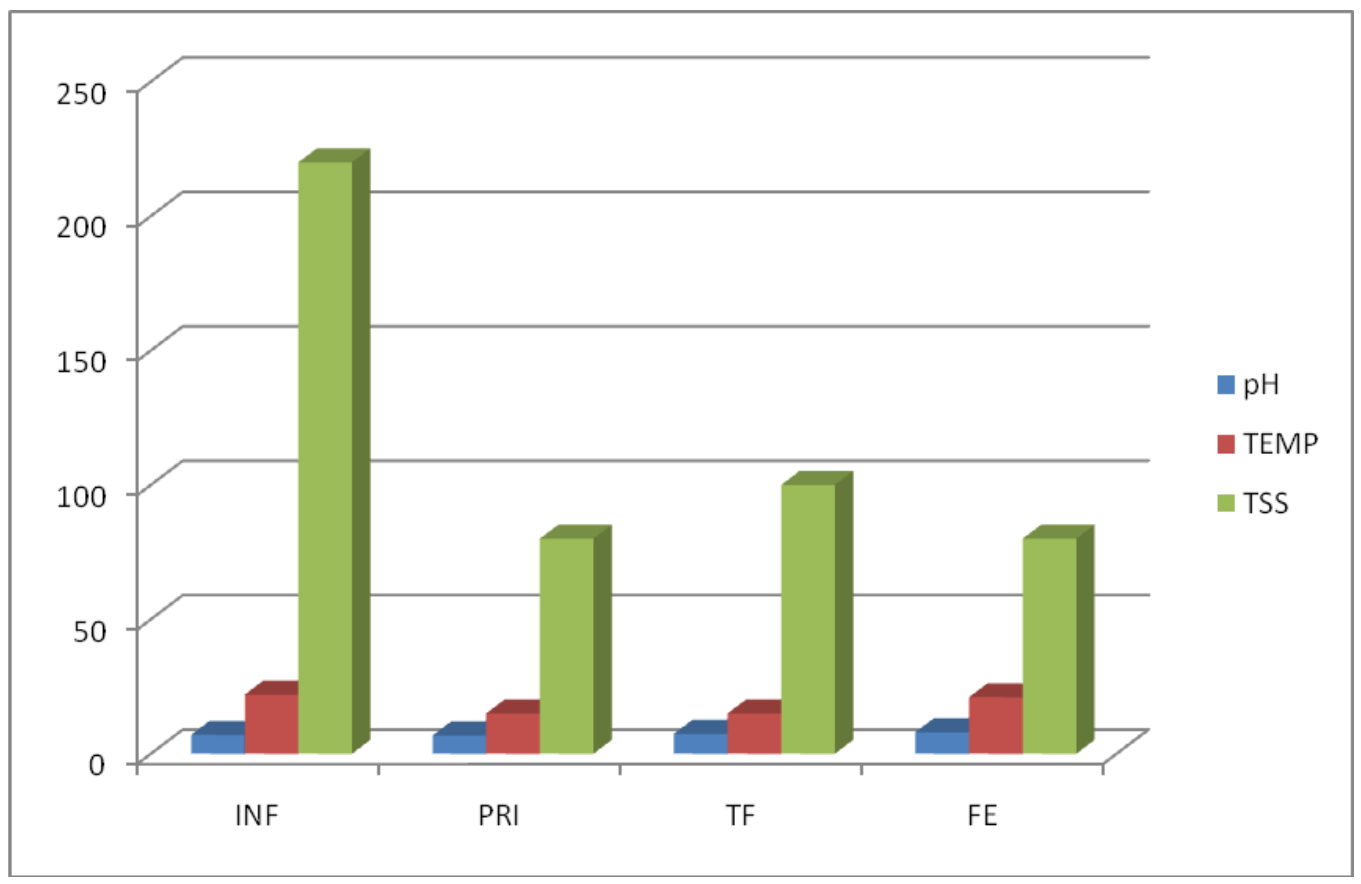

Figure 3.2 (a): Physicochemical parameters at the various sampling points -Wet season

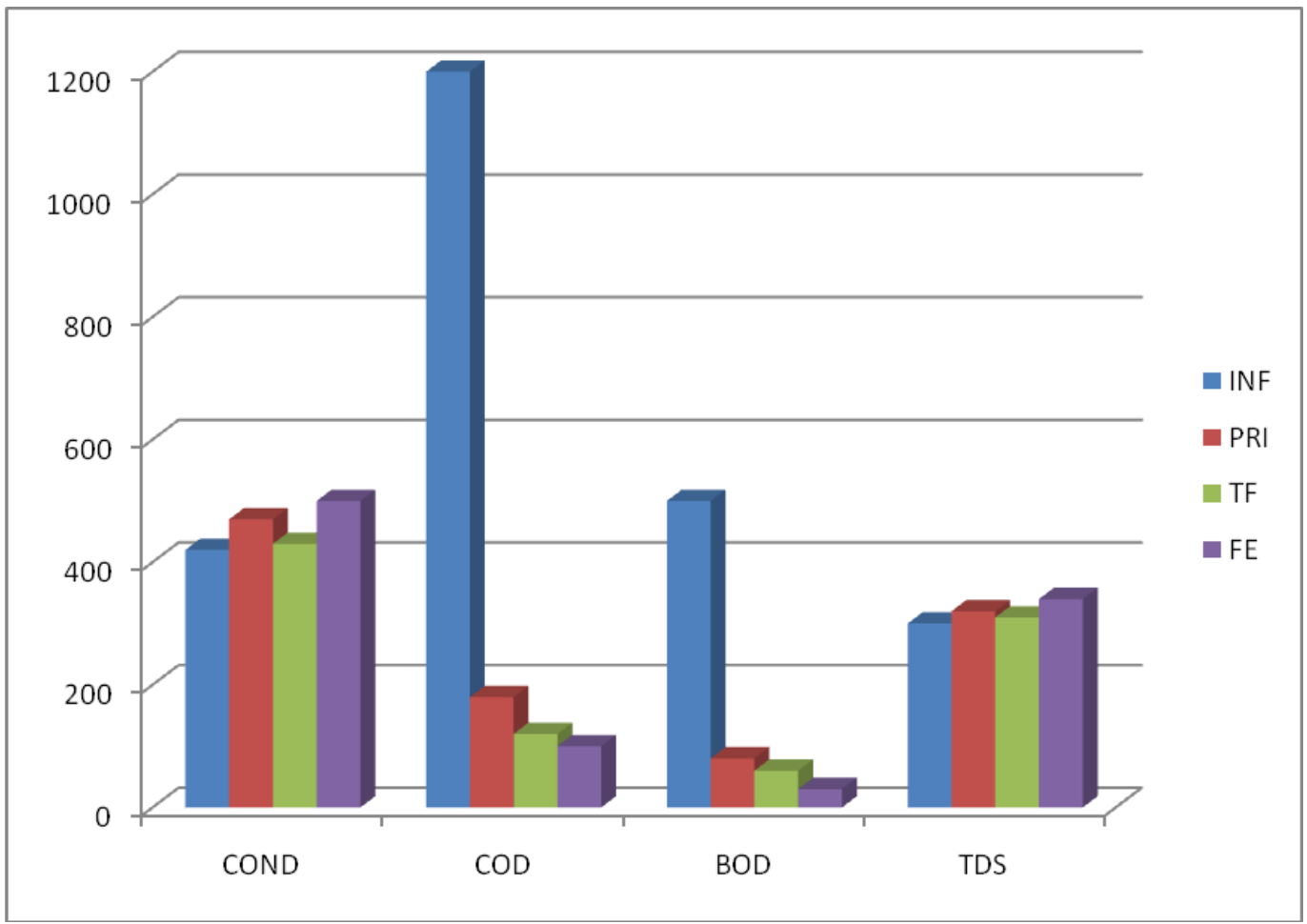

Figure 3.2 (b): Physicochemical parameters at the various points - Wet season

The parameters BOD, COD, COND, pH, TDS, TEMP and TSS were significantly $(<0.05)$ different in all the stages of treatment; screen and primary pond, trickling filter and oxidation ponds.

All the parameters; BOD, COD, COND, pH, TDS, TEMP, TSS and TC were significantly different $(\mathrm{p}<0.05)$ at 
the various treatment points; screen, primary pond, trickling filter and oxidation ponds.

Chemical oxygen demand, biological oxygen demand reduced consistently as the wastewater underwent treatment at the various points of treatment however, TDS, conductivity, temperature and $\mathrm{pH}$ were inconsistent in their reduction down from one point to another during the treatment process (Figure 1a, b, c and d).

The COD and BOD reduced consistently as the wastewater underwent treatment at the various stages of treatment but, TDS, conductivity, temperature and $\mathrm{pH}$ were inconsistent in their reduction from one point to the next (Figure 2a, b, c and d).

\section{Discussion}

All the physico chemical parameters were significantly different $(p<0.05)$ in all the stages of treatment at Huruma Sewage Treatment Plant during both dry and wet seasons. This could be due to the treatment processes improving at every stage (inlet, screen, primary pond, trickling filter, sedimentation pond, secondary pond and tertiary pond).

In the primary sedimentation pond the BOD could have been reduced by settlement and anaerobic digestion of organic matter at this pond as suggested by (Mara, 2003). Anaerobic treatment has been found to be more suited to wastewater with high BOD (IETC - UNEP, 2002) and therefore useful at reducing high concentrations of BOD and suspended solids at primary stage. This is also reported by (Mara, 2003) who found out that a properly designed anaerobic pond can achieve around $60 \%$ of BOD removal in one day retention time. The reduction of BOD could also be attributed to the settling of organic matter to form sludge at primary pond and the availability of large primary sedimentation ponds at the Sewage Treatment Plant that allowed the large organic load to be degraded allowing the anaerobic microbes to digest them adequately. Primary treatment can physically remove 20 to $30 \%$ of the BOD that is present in particulate form (Prescott et al.,2002). The trickling filter (TF) further reduced the $\mathrm{BOD}$ in the wastewater under treatment. The $\mathrm{TF}$ is an aerobic treatment system that utilizes microorganisms attached to a media to remove organic matter from wastewater that passes through the media (Mackne et al., 1998). With TF the organic material is converted to carbon dioxide, ammonia, nitrate, sulphate and phosphate in the extensive biofilm hence reducing the BOD (Martinko and Clark). The anaerobic and facultatively anaerobic processes in oxidation ponds removes organic matter leading to reduction of BOD. The algae, at the edges of these ponds could also have assisted in degradation of organic matter, hence reducing BOD. The presence of algae in the aerobic and facultative zones could have resulted in the efficient performance of these ponds.

Chemical oxygen demand is believed to be reduced partly by the same mechanisms responsible for reduction of BOD. Ramesh, (2004) defined COD as the amount of oxygen required for the chemical oxidation of the organic matter with the help of strong chemical oxidants. The oxygen demand associated with the microbial cells is only partially exerted during a BOD test; also some of the organic compounds measured by COD may not be metabolized by the microorganisms in either the BOD bottle or the biological treatment process.

The raw sewage had close to neutral $\mathrm{pH}$ during the two seasons. After the primary pond effluent passed through the trickling filter, the $\mathrm{pH}$ increased to alkaline during dry season and to neutral during wet season. This increase could be attributed to introduction of hydroxyl ions to the wastewater at the trickling filter. The algae at the periphery of Sewage Treatment Plant and at the ridges in the sedimentation tank could be responsible for introduction of hydroxyl ions into the wastewater thereby, increasing the $\mathrm{pH}$. This argument is supported by Mara and Pearson, (1998).

The results also portrayed that the $\mathrm{pH}$ increased during the two seasons after the trickling filter effluent passed the oxidation ponds. This increase in $\mathrm{pH}$ could be attributed to more hydroxyl ions being released into the wastewater under treatment, by the algae at the edges of the ponds. Fact supported by (Mackne et al., 1998). These authors demonstrated that denitrification occurs where oxygen levels are depleted and nitrate became the primary oxygen source of microorganisms. Nitrogen present in wastewater is a reduced form of ammonia and is removed during conventional wastewater treatment by two sequential biological processes; nitrification and denitrification (Tallec et al., 2006).

The temperature reduced after the influent passed through the screen and the primary pond during the two seasons. The temperature in the trickling filter effluent further reduced during dry season while it remained constant during wet season. This could be due to the fact that in the filter, sunshine cannot pass through the media to the cemented floor to heat the under drain wastewater. The rotating sprinklers at the trickling filters 
could also have brought about the cooling effect to the wastewater under treatment. After treatment in the ponds, the temperature of the treated effluents increased during the two study seasons. During the dry season of study, the increase of the temperature could have been due to heat from sun that heated these ponds directly because they are open.

Total dissolved solids and conductivity increased after the influent underwent treatment at the screen and primary pond. This could be due to the anaerobic breakdown of the organic and inorganic materials leading to the release of dissolved solids and hence the increase in the conductivity and TDS. After the trickling filter the TDS and conductivity reduced.

Total suspended solids reduced after the raw sewage passed through the screen and the primary pond. This could be due to removal of solids at the screen i.e. rags, sticks that could have been having suspended solids adsorbed to them (EPA, 2004). The screen could have also removed the suspended solids therefore reducing the TSS in the wastewater. The primary pond is normally associated with settling of suspended solids hence reducing the TSS. Further, primary sewage treatment follows the preliminary stage of treatment where more solid matter settles and about $40-60 \%$ of suspended solids are removed from sewage by settling (Tortora et al., 2010). The TSS increased after the primary pond effluent passed through the trickling filter. The increase in the TSS could be due to death flocs from the trickling filter, solids of the media and this construction itself might have peeled out and hence contributed to this increase.

The influent samples recorded higher amounts of the parameters during dry season than wet season and subsequently at the various stages of wastewater treatment. This difference in the level of parameters could be due to the dilution effect by the rain during wet season. Similarly to studies by Mara and Pearson, (1998), they demonstrated that the design parameters such as BOD and COD in oxidation ponds attain maximum values in the hot season and minimum values in the wet/cold season.

\section{Conclusion}

From the results of the study, it was concluded that seasonal variation does not affect the performance of conventional wastewater treatment plant. However, the wastewater treatment plant registered lower values of the parameters during wet season than during dry season

\section{References}

Akpor OB, Muchie B. Environmental and public health implications of wastewater quality. African Journal of Biotechnology. 2011 Mar 28; 10(13): 2379-87.

Chandra R, Singh S, Raj A. Seasonal bacteriological analysis of Gola river water contaminated with pulp paper mill waste in Uttaranchal, India. Environmental monitoring and assessment. 2006 Jul 1;118(1-3):393406.

Eaton, Andreio D., Lenore S. Clesceri, and A. E. Greenburg. "Standard methods for the examination of water and wastewater. Baltimore, Maryland, American Public Health Association.” (1995).

Environmental Protection Agency (EPA). Wastewater technology fact sheet trickling filters. EPA $832-\mathrm{F}-00$ $-014 ; 2000$.

Fatta, D., Anayiotou, S. and, I. An overview of the Water and Wastewater Management Practices in Cyprus, In: IWA Specialty Conference, Wastewater reclamation and reuse for sustainability, 2005 Jeju, Korea.

IETC - UNEP. Environmentally sound technologies for wastewater and storm water management: 2002.

Mackne, C., Lake, A., Casey, P., and Solomon, C. Trickling filters achieving filtration factsheet; 1998

Mara DD, Pearson HW. Design manual for waste stabilization ponds in Mediterranean countries. Lagoon Technology International Ltda; 1998.

Mara, D, and International Water Association. Design manual for waste stabilization ponds in India. IWA, 2003.

Martinko, M., and D. Clark. Biology of Microorganisms: Pearson International Edition. Pearson Publishers, 2009.

Prescott, LM.; Herley, JP.; and Klein, DA. Fifth edition Microbiology. McGraw - Hill (2002).

Ramesh, KJ. (2004). Environmental microbiology. Chania: MJP publishers

Shilton, Andy, ed. Pond treatment technology. IWA publishing, 2005.

Tallec, G., Garnier, J., Billen, G., Gousailles, M. Nitrous oxide emissions from secondary activated sludge in nitrifying conditions of urban wastewater treatment plants: effect of oxygenation level. Wat Res, 2006 a 40 (15), 2972-2980.

UNEP, Green Hills, Blue Cities: An Ecosystems Approach to Water Resources Management for African Cities. A Rapid Response Assessment, UNEP, Nairobi 2011

Wakelin, S.A.; Colloff, M.J.; Kookanal, R.S. Effect of wastewater treatment plant effluent on microbial function 
and community structure in the sediment of a freshwater stream with variable seasonal flow. Appl. Environ. Microbiol. 2008, 74, 2659-2668. 